www.jmscr.igmpublication.org

Impact Factor 5.84

Index Copernicus Value: 83.27

ISSN (e)-2347-176x ISSN (p) 2455-0450

crossref DOI: _https://dx.doi.org/10.18535/jmscr/v5i3.84

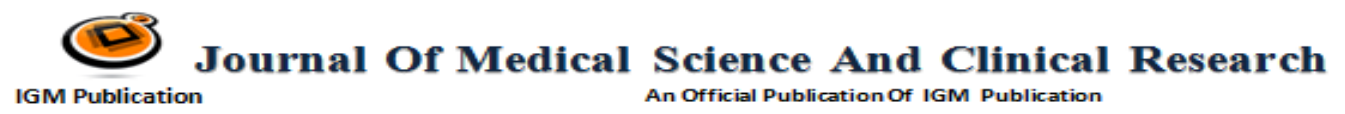

\title{
A Unique Case of Accidental Ipsilateral Retrograde Internal Juglar Vein Cannulation
}

\author{
Author \\ Dr Kriti Singh \\ Batra Hospital and Medical Research Center, New Delhi
}

Central Venous Catheters (CVC) play a pivotal role when it comes to managing critical patients for Central Venous Pressure (CVP) monitoring and administration of inotropes, pressor agents, blood products, and for frequent blood sampling. Ultrasound (USG) guided central venous cannulation is nowadays a preferred modality, due to lower errors while insertion and lesser complication rates. ${ }^{[1][2]}$ However, it does not prevent or help to detect catheter misplacement.

We present a case of a 37-year-old female, known case of carcinoma cervix posted for Wertheim's hysterectomy. After induction of anaesthesia, it was decided to perform central venous catheterization. The right internal juglar vein (IJV) was cannulated with help of USG using the Seldinger's technique with a 7 Fr double-lumen indwelling catheter. During guide wire insertion, no cardiac arrhythmias were seen. Blood was aspirated from the proximal as well as the distal port of the CVC. However, atrial waveforms were not seen during CVP tracing. This raised our index of suspicion, and a Chest X-Ray was done to confirm the catheter placement. The X-ray revealed only a part of the CVC which was seen retrograde in the ipsilateral IJV, however the tip was not seen. Another X-ray of the neck was done which revealed the tip of the CVC near the superior juglar venous bulb. The catheter was then removed and successful re-catheterisation was done. We postulate that the upward direction of the J-tip guidewire along with trendelenburg position might have contributed to the retrograde IJV cannulation. ${ }^{[3][4]}$

Studies claim that the incidence of malposition of CVCs during IJV cannulation is around 2\%. ${ }^{[5]}$ There are very few reports of accidental retrograde ipsilateral IJV cannulation in the past. The chances of a catheter misplacement in the right IJV is unlikely, due to its straight vertical course. It is necessary to confirm the placement of the CVC tip, since inadvertent placement may lead to complications like pneumothorax and arterial cannulation. ECG guidance and presence of arrhythmias guide about the placement of the tip in the superior vena cava. ${ }^{[6]}$ A USG reduces complications like arterial cannulation but it does not guide about the tip placement. The placement of CVC tip at the superior vena cava-right atrial junction is most accurately detected by Trans Esophageal Echocardiography and fluoroscopy but it is not always feasible due to lack of equipment or high cost. ${ }^{[7]}$ Hence we recommend that a Chest X-Ray should be done after a CVC 


\section{JMSCR Vol||05||Issue||03||Page 18805-18806||March}

cannulation, and any malpositioning should be corrected with immediate effect, to avoid further complications.

Image 1: Chest X-Ray: CVC is seen retrograde in IJV. Tip is not visualized.

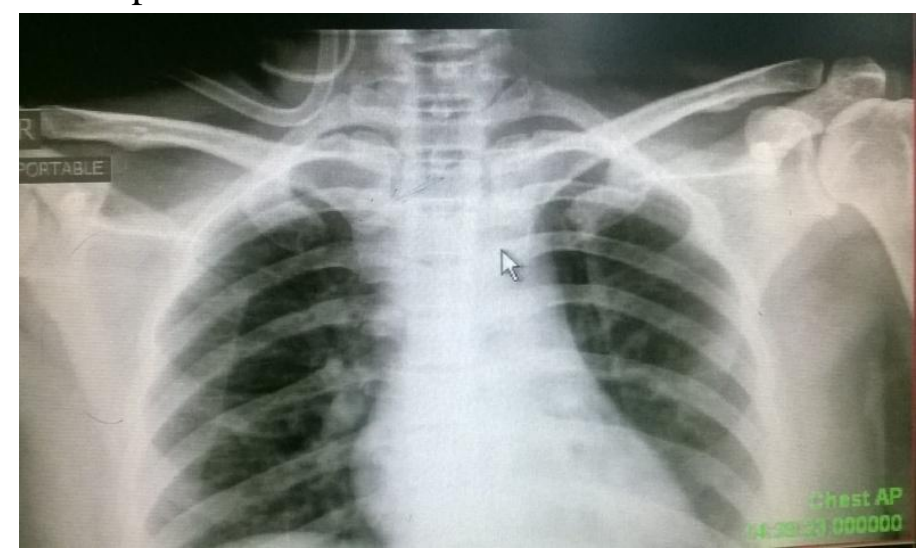

Image 2: X-ray Neck PA View. CVC tip is seen near the superior Juglar bulb

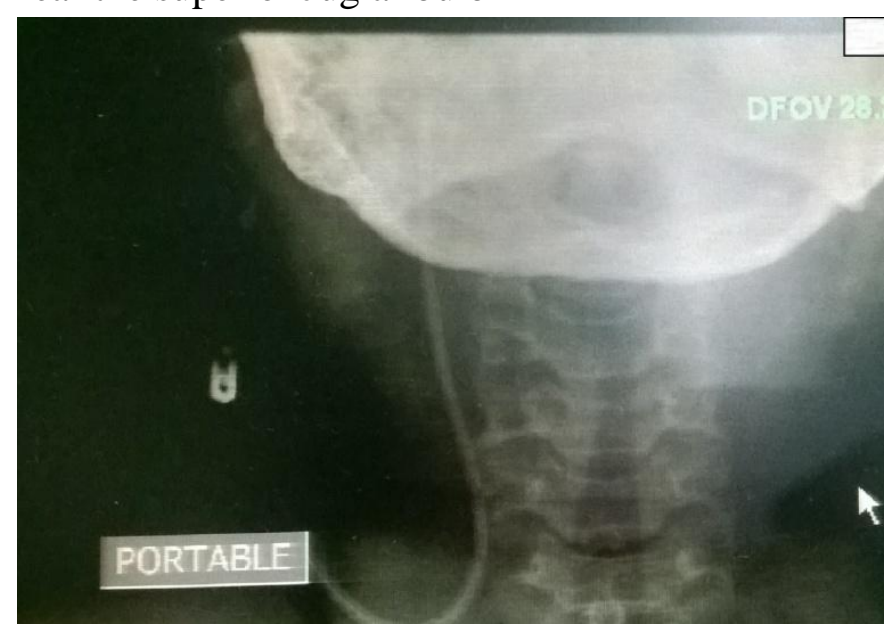

Image 3: X-Ray Neck Lateral View

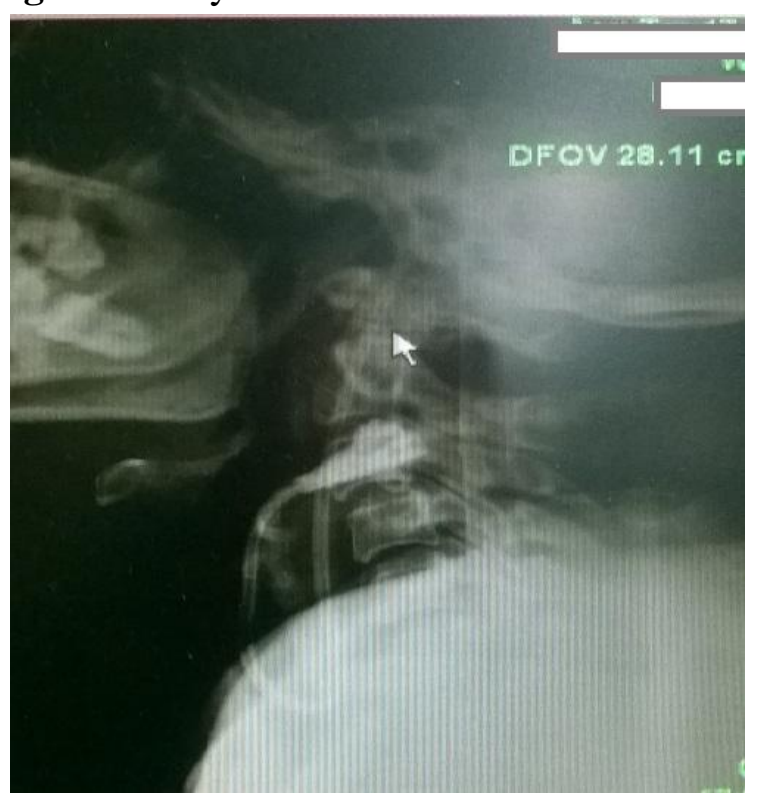

\section{References}

1. Abboud PA, Kendall JL. Ultrasound guidance for vascular access. Emerg Med Clin North Am. 2004; 22(3):749-73.

2. Denys BG, Uretsky BF, Reddy PS. Ultrasound-assisted cannulation of the internal jugular vein. A prospective compareison to the external landmark-guided technique. Circulation. 1993;87(5):155762.

3. Park HP, Jeon Y, Hwang JW, Han SH, Bahk JH, Oh YS. Influence of orientations of guidewire tip on the placement of subclavian venous catheters. Acta Anaesthesiol Scand. 2005;49:1460-3.

4. Tripathi M, Dubey PK, Ambesh SP. Direction of the J-tip of the guidewire, in seldinger technique, is a significant factor in misplacement of subclavian vein catheter: a randomized, controlled study. Anesth Analg 2005;100:21-4.

5. Zaman MH, Mitra P, Bondi E, Gintautas J, Abadir AR. A rare malposition of the central venous catheter. Chest. 1990; 98:768-70.

6. Starr DS, Cornicelli S. EKG guided placement of subclavian CVP catheters using J-wire. Ann Surg. 1986;204:673-6.

7. Arellano R, Nurmohamed A, Rumman A, Day AG, Milne B, Phelan R, et al. The utility of transthoracic echocardiography to confirm central line placement: An observational study. Can J Anaesth. 2014;61:340-6. 